\section{BMJ Open} Ophthalmology

\title{
Opacification of hydrophilic intraocular lenses associated with vitrectomy and injection of intraocular gas
}

\author{
Arie L Marcovich, ${ }^{1}$ Tamer Tandogan, ${ }^{2}$ Mor Bareket, ${ }^{1}$ Eva Eting, ${ }^{3}$ Ifat Kaplan-Ashiri, ${ }^{4}$ \\ Amir Bukelman, ${ }^{1}$ Gerd U Auffarth, ${ }^{2}$ Ramin Khoramnia ${ }^{2}$
}

\begin{abstract}
To cite: Marcovich AL, Tandogan T, Bareket M, et al. Opacification of hydrophilic intraocular lenses associated with vitrectomy and injection of intraocular gas. BMJ Open Ophthalmology 2018;3:e000157. doi:10.1136/ bmjophth-2018-000157
\end{abstract}

- Additional material is published online only. To view please visit the journal online (http://dx.doi.org/10.1136/ bmjophth-2018-000157)

ALM and TT contributed equally.

Received 10 March 2018 Revised 17 September 2018 Accepted 13 0ctober 2018

Check for updates

C A Author(s) (or their employer(s)) 2018. Re-use permitted under CC BY-NC. No commercial re-use. See rights and permissions. Published by BMJ.

${ }^{1}$ Department of Ophthalmology, Kaplan Medical Center, Rehovot, Israel

${ }^{2}$ David J Apple International Laboratory for Ocular Pathology, Department of Ophthalmology, University of Heidelberg, Heidelberg, Germany ${ }^{3}$ Department of Ophthalmology, Assaf Harofeh Medical Center, Zeriffin, Israel

${ }^{4}$ Department of Chemical Research Support, Weizmann Institute of Science, Rehovot, Israel

Correspondence to Dr Arie L Marcovich; arie. marcovich@gmail.com

\section{ABSTRACT}

Objective To report 11 cases of intraocular lens (IOL) opacification after pars plana vitrectomy (PPV) involving intravitreal gas injection.

Methods and analysis Eleven cases of hydrophilic IOLs that opacified following PPV with intravitreal gas injection are described. Eight IOLs were explanted and analysed by light microscopy and scanning electron microscopy. Staining with alizarin red and von Kossa stains, as well as energy dispersive X-ray spectroscopy (EDX) were performed. Three IOLs were not explanted. The surgeons attached the clinical data.

Results The IOLs were hydrophilic acrylic produced by six manufacturers. Six patients underwent primarily phacoemulsification with IOL implantation. PPV with intravitreal gas injection was performed 3 months -6 years afterwards. The other five patients underwent combined phacoemulsification with IOL implantation and PPV with intravitreal gas injection. IOL opacification was recorded 1 month -6 years after PPV. In eight patients, the IOLs were explanted 1 month-9 years after opacification was noticed. In three patients, the opacified IOL was not explanted. IOLs had opacified mainly anteriorly at the pupillary entrance or capsulorhexis opening. Light microscopy demonstrated granular surface deposits on the IOLs that stained positive for calcium by alizarin red and von Kossa stains. EDX analysis of the deposits detected calcium and phosphorus. Conclusions Hydrophilic acrylic IOLs can opacify due to calcium deposition after PPV and intravitreal gas injection and may require IOL explantation. A hydrophobic IOL may be preferred when a simultaneous phacoemulsification and vitrectomy with intravitreal gas is performed.

\section{INTRODUCTION}

Opacification of hydrophilic acrylic intraocular lenses (IOLs) following intraocular gas injection has been described with numerous IOL models. ${ }^{1-9}$ In most reports, the opacification occurred following intracameral injection of air, sulfur hexafluoride (SF6) or perfluoropropane (PFP) during Descemet's stripping endothelial keratoplasty (DSAEK), Descemet's membrane endothelial keratoplasty (DMEK) or intracameral gas injection for treatment of Descemet's membrane detachment following cataract surgery. ${ }^{1-7}$ In several reports, the opacification occurred

\section{Key messages}

What is already known about this subject?

- Opacification of hydrophilic acrylic intraocular lens (IOL) has been mainly described after air injection into the anterior chamber during endothelial keratoplasty. Only few sporadic cases have been published to date following pars plana vitrectomy with intravitreal gas injection.

\section{What are the new findings?}

- These opacified IOLS exhibited calcification of the anterior surface despite the injection of gas into the vitreous. Migration of gas to the anterior chamber that was documented in two cases may elucidate this phenomenon.

\section{How might these results change the focus of} research or clinical practice?

This series emphasises the importance of this complication, the incidence of which is expected to increase with the increasing number of pars plana vitrectomies performed worldwide. In eyes already implanted with a hydrophilic acrylic IOL, prevention of migration of gas to the anterior chamber may be beneficial. Surgeons should be aware that in combined procedures, implantation of a hydrophobic IOL can prevent this complication.

after vitrectomy with intravitreal gas injection. In all these cases, the opacification appeared almost exclusively on the anterior surface of the IOL although the gas was injected into the vitreous. ${ }^{6-10}$ The typical appearance in most cases is surface irregularity confined to the central part of the optic, which corresponds to the opening of the pupil or the anterior capsulorhexis. $^{6-10}$ Laboratory analysis with scanning electron microscope (SEM) using energy dispersive x-ray spectroscopy (EDX) or staining with alizarin red and von Kossa stains demonstrates deposition of calcium (Ca) on IOL surfaces. ${ }^{6-10}$

Here we present a series of 11 hydrophilic acrylic IOLs from several manufacturers that opacified after injection of intravitreal gas during vitrectomy. This series is important in 
light of the rising number of PPV surgeries performed in recent years, especially in the elderly population. ${ }^{11}$ Therefore, we anticipate a rising incidence of hydrophilic acrylic IOL opacifications in the future, hence the importance of retinal surgeons' awareness and recognition of this complication.

\section{MATERIALS AND METHODS}

Eleven cases of hydrophilic IOLs that opacified following PPV with intravitreal gas injection are described. Eight explanted IOLs were sent for analysis by the surgeon to the Department of Ophthalmology, Kaplan Medical Center, Rehovot, Israel, and the David Apple International Laboratory for Ocular Pathology, Department of Ophthalmology, University of Heidelberg, Germany. The explanted IOLs were analysed by light microscopy and SEM. IOLs were stained for calcium with $1.0 \%$ alizarin red and von Kossa stains. Elemental analysis by EDX was performed. SEM was performed by Zeiss Supra 55 or Zeiss Ultra 55 microscopes at the Weizmann Institute of Science, Rehovot, Israel, or at the Max Planck Institute for Polymer Research, Mainz, Germany. Three IOLs were not explanted. The surgeons attached information about the IOLs, patients and surgical procedures. The study proposal was reviewed by the chairperson of the ethics committee at the Kaplan Medical Center, Rehovot, which confirmed that ethics committee approval was not required.

\section{RESULTS}

The characteristics of the 11 cases and the surgical settings are depicted in tables 1 and 2. Seven patients were women and four were men. The mean age at IOL implantation was 63.2 years (range: $50-76$ years). The IOLs were implanted between June 2003 and October 2016. Six patients (cases 1, 2, 4, 5, 6 and 7) underwent primarily phacoemulsification with IOL implantation. Five of these surgeries were uneventful. In one patient (case 2), anterior vitrectomy was performed, and the IOL was implanted in the sulcus. In six patients with prior IOL implantation, PPV with intravitreal gas injection was performed 3 months -6 years after cataract surgery. At the time of PPV, the IOLs were clear. The other five patients (cases 3, 8, 9, 10 and 11) underwent simultaneous phacoemulsification with IOL implantation and PPV with intravitreal gas injection. Three patients underwent two PPV surgeries (cases 3, 5 and 9). In one of them (patient 5) PPV was performed before phacoemulsification and IOL implantation, and in another patient (9) the IOL opacified after the first PPV. In cases 1, 2, 3 and 7, the gas fully expanded in the posterior chamber postoperatively, but this was not mentioned in medical files of other cases. Elevated postoperative intraocular pressure (IOP) was observed in three patients (1,2 and 7). Elevated IOP was not mentioned in the operative notes that were available or in patient charts before IOL explantation.

General diseases, prior ocular history and best-corrected visual acuity (BCVA) before and after IOL explantation are described in online supplementary table 1. Part of the data was not provided by the surgeons. Two of the patients had diabetes, five had hypertension and one suffered from asthma. Before explantation, BCVA ranged from light perception to $6 / 15$. After IOL exchange BCVA improved in three patients to $6 / 10$ (cases 1,6 and 7) and in one patient with poor macular function it improved from light perception to 6/60 (case $3)$. In one eye BCVA remained counting fingers due to macular atrophy (case 2) and in one patient it worsened from $6 / 21$ to $6 / 30$ (case 8 ).

The IOLs were produced by six manufacturers (table 2). Opacification of the IOL was first noted 1 month-6 years after PPV during regular clinic visits. In eight patients, the IOLs were explanted between July 2013 and July 2015. The explantation was performed 1 month-9 years after opacification was first noted. During this period, the opacity became denser and obscured vision. One IOL was explanted with the capsular bag (case 5). In three patients, the opacified IOL was not explanted: two of them (cases 9 and 10) had poor visual potential; the third patient (case 11) experienced glare and blurred vision. However, her visual acuity was $6 / 12$, and she rejected IOL explantation. IOL opacification occurred mainly on the anterior aspect, forming a round rough surface that corresponded to the pupillary entrance or the capsulorhexis margin.(figures $1 \mathrm{~A}, \mathrm{~B}$, 2A, B, C, 3C). In the sulcus implanted IOL (case 2), the opacification extended over the entire optic area as well as part of the haptics (figure $4 \mathrm{~A}, \mathrm{~B}, \mathrm{C}$ ). In one patient (case 3), prominent opacification occurred also on the posterior surface of the IOL(figure $5 \mathrm{~A}, \mathrm{D}$ ). This patient was treated previously by pan-retinal laser photocoagulation for proliferative diabetic retinopathy (PDR) and triamcinolone intravitreal injections for macular oedema. He underwent PPV twice: the first PPV combined with phacoemulsification was performed for ERM with SF6 injection. After 4 months, the patient developed RD and underwent a second PPV with PFP injection (fully expanded gas bubble postoperatively). IOL opacification was first noted 11 months after the second operation. The IOL was explanted 8 years later due to inability to examine the fundus for diabetic retinopathy follow-up. Neodymium-doped yttrium aluminium garnet capsulotomy before PPV was performed only in one patient (case 2) that underwent anterior vitrectomy during cataract surgery with vitreous loss.

Laboratory examination by light microscopy demonstrated granular deposits on the IOL surface that stained positive for Ca by alizarin red and von Kossa method (figure 2A, B). SEM showed granular deposits on the surface of the IOL in different patterns (figures 1, 4 and 5). EDX demonstrated that the granules consisted of $\mathrm{Ca}$ and phosphorus $(\mathrm{P})$ (figures 2D, 4, 5D). The granules were present on and below the anterior surface of the IOLs. 


\begin{tabular}{|c|c|c|c|c|c|}
\hline & $\begin{array}{l}\text { Age at IOL } \\
\text { implantation } \\
\text { /sex }\end{array}$ & $\begin{array}{l}\text { Phaco date/ } \\
\text { combined with PPV }\end{array}$ & Indication for PPV & PPV date & $\begin{array}{l}\text { Gas injected and } \\
\text { follow-up }\end{array}$ \\
\hline 1 & $61 / F$ & June 2003. & $\mathrm{MH}$ & January 2009 & $\begin{array}{l}\text { PFP } \\
\text { (100\% expansion). } \\
\text { Secondary } \\
\text { glaucoma treated } \\
\text { by drainage of gas. }\end{array}$ \\
\hline 2 & $71 / \mathrm{F}$ & $\begin{array}{l}\text { March } 2006 \\
\text { phaco+anterior } \\
\text { vitrectomy. IOL } \\
\text { implanted into } \\
\text { sulcus. }\end{array}$ & $\mathrm{RD}$ & January 2010 & $\begin{array}{l}\text { PFP (100\% } \\
\text { expansion) } \\
\text { secondary } \\
\text { glaucoma and } \\
\text { migration of gas to } \\
\text { anterior chamber } \\
\text { treated by drainage } \\
\text { of gas. }\end{array}$ \\
\hline \multirow[t]{2}{*}{3} & $56 / \mathrm{M}$ & $\begin{array}{l}\text { August } 2005 \\
\text { combined with PPV. }\end{array}$ & ERM & August 2005 & $\begin{array}{l}\text { SF6 } \\
\text { (100\% expansion). }\end{array}$ \\
\hline & & Second PPV. & $\mathrm{RD}$ & December 2005 & PFP. \\
\hline 4 & $57 / F$ & $\begin{array}{l}\text { January } 2009 \\
\text { combined with PPV } \\
\text { and scleral buckle. }\end{array}$ & $\mathrm{RD}$ & August 2009 & PFP 60\%. \\
\hline 5 & $76 / \mathrm{M}$ & April 2009. & $\mathrm{MH}$ & 2009 & Gas unknown. \\
\hline 6 & $63 / \mathrm{M}$ & September 2011. & Unknown & May 2014 & Gas unknown. \\
\hline 7 & $60 / F$ & February 2013. & $\mathrm{RD}$ & May 2013 & $\begin{array}{l}\text { Gas unknown } \\
\text { (100\% expansion). } \\
\text { Secondary } \\
\text { glaucoma. }\end{array}$ \\
\hline 8 & $63 / F$ & $\begin{array}{l}\text { May } 2012 \\
\text { combined with PPV. }\end{array}$ & ERM & May 2012 & PFP. \\
\hline \multirow[t]{2}{*}{9} & $69 / F$ & $\begin{array}{l}\text { June } 2008 \\
\text { combined with PPV. }\end{array}$ & $\mathrm{RD}$ & June 2008 & Gas unknown. \\
\hline & & & $\mathrm{RD}$ & September 2015 & PFP. \\
\hline 10 & $50 / \mathrm{M}$ & $\begin{array}{l}\text { October } 2016 \\
\text { combined with PPV. }\end{array}$ & $\mathrm{RD}$ & October 2016 & $\begin{array}{l}\text { PFP. } \\
\text { Gas migration to } \\
\text { anterior chamber. }\end{array}$ \\
\hline 11 & $69 / F$ & $\begin{array}{l}\text { March } 2008 \\
\text { combined with PPV. }\end{array}$ & ERM & March 2008 & SF6. \\
\hline
\end{tabular}

ERM, epiretinal membrane; F, female; IOL, intraocular lens; M, male; MH, macular hole; PFP, Perfluoropropane; RD, retinal detachment; SF6, sulfur hexafluoride; phaco, phacoemulsification.

\section{DISCUSSION}

Opacification of hydrophilic acrylic IOLs following intracameral injection of air has been reported following endothelial keratoplasty (DSAEK and DMEK) $)^{1-4} 7$ or Descemet's membrane detachment repair. ${ }^{5}$ The opacified area matched the pupillary or capsulorhexis opening at the anterior surface of the IOL. ${ }^{1-7}$ Laboratory analysis by histochemical staining, SEM and EDX of explanted opacified IOLs detected deposition of $\mathrm{Ca}$ and $\mathrm{P}$ on the anterior surface and subsurface. ${ }^{1-7}$ The exact mechanism of calcification of the exposed IOL surface is under investigation. A hypothesis of local damage to the hydrophilic IOL surface due to the direct contact with air/gas at the exposed area has been suggested. This damage may lead to $\mathrm{Ca} / \mathrm{P}$ deposition from the aqueous humour. ${ }^{236}$ In their information for users (IFUs), hydrophilic IOL manufacturers alert against IOL dehydration. ${ }^{12}{ }^{13}$ In the Medicontur IFU, it is stated that a hydrophilic IOL that was kept in open air for longer than 1 min should be discarded. ${ }^{12}$ However, a similar pattern of hydrophilic IOL calcification has been observed when gas was injected to the vitreous during PPV surgery. ${ }^{8-10}$ Werner et $a l^{2}$ suggested that leakage of gas to the anterior chamber may explain the same observation. This explanation is supported by the findings in our 10th patient. In this patient, the gas migrated to the anterior chamber 1 day postoperatively. Drying of the anterior surface of the IOL was noted (figure 3A). Following gas disappearance, the IOL looked transparent on the 1-month follow-up visit (figure 3B). Examination 8 months postoperatively detected deposits on the 
Table 2 Intraocular lens (IOL) data

\begin{tabular}{|c|c|c|c|c|c|c|}
\hline & IOL type & Surgical setting & $\begin{array}{l}\text { Opacification first } \\
\text { noted }\end{array}$ & $\begin{array}{l}\text { Explantation } \\
\text { date }\end{array}$ & Site of opacification & $\begin{array}{l}\text { Nd:YAG } \\
\text { capsulotomy } \\
\text { before PPV }\end{array}$ \\
\hline 1 & Hanita B lens & $\begin{array}{l}\text { Kaplan Medical } \\
\text { Center, Rehovot, } \\
\text { Israel }\end{array}$ & $\begin{array}{l}6 \text { months after PPV } \\
\text { July } 2009 .\end{array}$ & $\begin{array}{l}\text { February } \\
2014\end{array}$ & $\begin{array}{l}\text { Anterior opacity at } \\
\text { the capsulorhexis } \\
\text { area. }\end{array}$ & No \\
\hline 2 & Xcellence Idea & $\begin{array}{l}\text { Kaplan Medical } \\
\text { Center, Rehovot, } \\
\text { Israel }\end{array}$ & $\begin{array}{l}8 \text { months after PPV } \\
\text { September } 2010 .\end{array}$ & June 2014 & $\begin{array}{l}\text { Anterior surface of } \\
\text { almost entire optic } \\
\text { and part of haptics. }\end{array}$ & Yes \\
\hline 3 & Hanita B lens & $\begin{array}{l}\text { Assaf Harofeh Medical } \\
\text { Center, Zeriffin, Israel }\end{array}$ & $\begin{array}{l}11 \text { months after } \\
\text { second PPV } \\
\text { November } 2006 .\end{array}$ & July 2015 & $\begin{array}{l}\text { Anterior and } \\
\text { posterior entire } \\
\text { optic and part of } \\
\text { haptics. }\end{array}$ & No \\
\hline 4 & $\begin{array}{l}\text { Biotech vision } \\
\text { care Eyecryl }\end{array}$ & $\begin{array}{l}\text { Nordsjællands } \\
\text { Hospital, Hillerød, } \\
\text { Denmark }\end{array}$ & $\begin{array}{l}3.5 \text { years after PPV } \\
\text { February } 2013 .\end{array}$ & August 2014 & $\begin{array}{l}\text { Anterior opacity at } \\
\text { the pupillary area. }\end{array}$ & No \\
\hline 5 & $\begin{array}{l}\text { Rayner } \\
\text { Superflex } \\
\text { Aspheric } 920 \\
\text { hours }\end{array}$ & $\begin{array}{l}\text { Northern Eye } \\
\text { Consultants, } \\
\text { Northpark Hospital, } \\
\text { Australia }\end{array}$ & $\begin{array}{l}6 \text { years after PPV } \\
2015 .\end{array}$ & 2015 & $\begin{array}{l}\text { Anterior opacity at } \\
\text { the pupillary area. }\end{array}$ & No \\
\hline 6 & $\begin{array}{l}\text { Rayner M-flex } \\
630 \mathrm{~F}\end{array}$ & $\begin{array}{l}\text { Clinica Marly de } \\
\text { Bogota, Bogota, } \\
\text { Columbia }\end{array}$ & $\begin{array}{l}3 \text { months after PPV } \\
\text { August } 2014 .\end{array}$ & $\begin{array}{l}\text { February } \\
2015\end{array}$ & $\begin{array}{l}\text { Anterior opacity at } \\
\text { the pupillary area. }\end{array}$ & No \\
\hline 7 & $\begin{array}{l}\text { Zeiss CT } \\
\text { Asphina 409M }\end{array}$ & $\begin{array}{l}\text { Augenklinik } \\
\text { Universitätsallee } \\
\text { Bremen } \\
\text { Germany }\end{array}$ & $\begin{array}{l}1 \text { month after PPV } \\
\text { July } 2013 .\end{array}$ & July 2013 & $\begin{array}{l}\text { Anterior opacity at } \\
\text { the pupillary area } \\
\text { extending slightly } \\
\text { beyond it. }\end{array}$ & No \\
\hline 8 & $\begin{array}{l}\text { U.S. optics SL- } \\
902\end{array}$ & $\begin{array}{l}\text { Lugansk region center } \\
\text { of eye diseases, } \\
\text { Lugansk, Ukraine }\end{array}$ & $\begin{array}{l}1.5 \text { years after PPV } \\
\text { May } 2012 .\end{array}$ & January 2014 & $\begin{array}{l}\text { Anterior opacity at } \\
\text { the pupillary area. }\end{array}$ & No \\
\hline 9 & $\begin{array}{l}\text { Rayner C-flex } \\
\text { Aspheric 570C }\end{array}$ & $\begin{array}{l}\text { Kaplan Medical } \\
\text { Center, Rehovot, } \\
\text { Israel }\end{array}$ & $\begin{array}{l}1.5 \text { years after PPV } \\
\text { February } 2010 .\end{array}$ & Not explanted & $\begin{array}{l}\text { Anterior opacity at } \\
\text { the pupillary area. }\end{array}$ & No \\
\hline 10 & Hanita C lens & $\begin{array}{l}\text { Kaplan Medical } \\
\text { Center, Rehovot, } \\
\text { Israel }\end{array}$ & $\begin{array}{l}6 \text { months after PPV } \\
\text { October } 2016 .\end{array}$ & Not explanted & $\begin{array}{l}\text { Anterior opacity at } \\
\text { the pupillary area. }\end{array}$ & No \\
\hline 11 & $\begin{array}{l}\text { Rayner C-flex } \\
\text { Aspheric 570C }\end{array}$ & $\begin{array}{l}\text { Kaplan Medical } \\
\text { Center, Rehovot, } \\
\text { Israel }\end{array}$ & $\begin{array}{l}3 \text { years after PPV } \\
2008 .\end{array}$ & Not explanted & $\begin{array}{l}\text { Anterior opacity at } \\
\text { the pupillary area. }\end{array}$ & No \\
\hline
\end{tabular}

Nd:YAG, neodymium-doped yttrium aluminium garnet; PPV, pars plana vitrectomy.

anterior IOL surface at the pupillary entrance (figure 3C). However, in many reported cases, the presence of gas in the anterior chamber was not mentioned. ${ }^{6-10}$ In these cases, the mechanism of opacification may be different. We hypothesise that filling of the vitreous cavity with slowly dissolving gas for a long period may relatively dehydrate the IOL despite intact posterior capsule. IOL dehydration may occur during sleep or while patient is supine, even in partially filled vitreous cavity, due to direct contact between gas and IOL. The dehydration may induce chemical alterations on the IOL surface. Later, $\mathrm{Ca} / \mathrm{P}$ from the aqueous humour is deposited in the exposed areas. Our cases support this hypothesis. In 9 out of our 11 cases of in-the-bag IOLs (cases 1, 4-11; table 1), the affected area is the anterior central part of the optic at the pupillary or capsulorhexis opening with sparing of the covered areas of the IOL (figure 1A, B, (figure 2A,B, C), (figure 3C). In case $2, \mathrm{Ca} / \mathrm{P}$ deposits were present all over the anterior optic and haptics (figure 4A, B, C), because the IOL was implanted in the sulcus and therefore not covered by the capsule anteriorly. This observation may indicate that the contact with the aqueous humour is responsible for the deposition of the $\mathrm{Ca} / \mathrm{P}$ on the exposed IOL surface. In one patient (case 3), prominent opacification occurred also on the posterior surface of the IOL (figure $5 \mathrm{~A}, \mathrm{~B}$, $\mathrm{C}, \mathrm{D})$. This is the first report of $\mathrm{Ca} / \mathrm{P}$ deposition on the posterior IOL surface after intraocular gas injection. The patient had PDR and underwent PPV twice, 4 months apart, with fully expanded gas bubble in the posterior chamber after the second PPV. The deposition of $\mathrm{Ca} / \mathrm{P}$ 

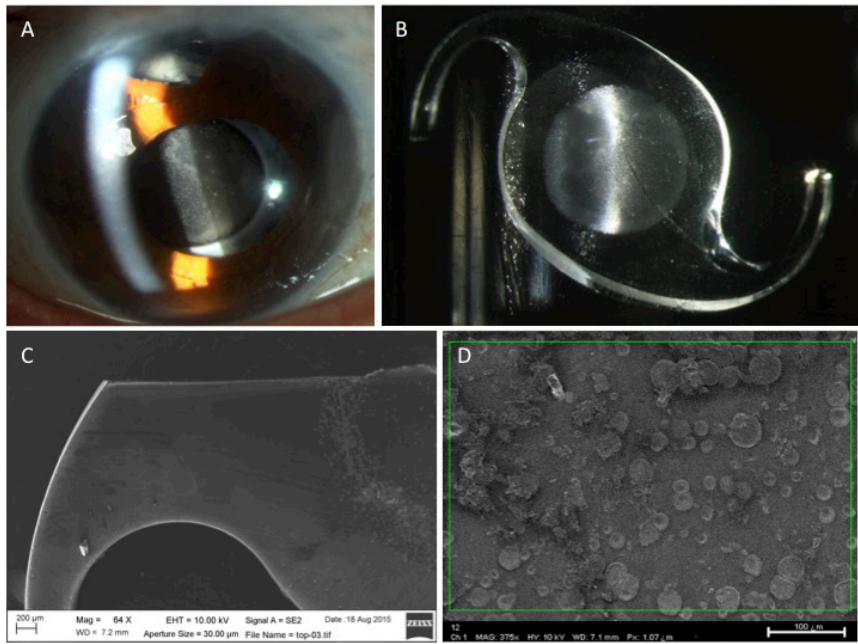

Figure 1 Case 1: (A) clinical photograph showing opacification of a hydrophilic IOL at the edge of the anterior capsulorhexis. (B) Photograph of the explanted $\mathrm{IOL}$ with a rough central anterior surface limited to the area of the capsulorhexis opening. (C and D) Low and high magnification image by SEM, demonstrating the sediments on the anterior optic. IOL, intraocular lens; SEM, scanning electron microscopy.

in this patient on the posterior IOL surface (figure $5 \mathrm{C}$, D) could result from the disruption of the blood-retinal barrier that occurs in PDR. A study on Ca and P levels in the aqueous humour of eyes of patients with diabetes found increased $\mathrm{P}$ levels compared with non-PDR or otherwise healthy patients. Ca levels did not differ between the groups. ${ }^{14}$ Elevated aqueous $\mathrm{P}$ levels may explain the extensive IOL $\mathrm{Ca} / \mathrm{P}$ sedimentation that occurred in this patient. The reason why certain eyes develop IOL deposits is uncertain. In DSAEK surgery, a correlation to repeated air/gas injections has been described. ${ }^{23}$ In cases 1,2 and 7 , fully expanded gas bubble in the posterior chamber with subsequent elevated IOP was detected postoperatively, and partial gas removal was performed in two cases. Elevated IOP was not reported in the available operative notes. When inflating the eye totally with gas, there is no fluid meniscus that may prevent the IOL from drying leading to surface modifications that promote sedimentation of $\mathrm{Ca} / \mathrm{P}$. Different morphological patterns of $\mathrm{Ca} / \mathrm{P}$ deposits (volcano, target and knob-like elevations) have been demonstrated. ${ }^{6}{ }^{9}$ These sediments may extend deeper into the body of the IOL or consist of subsurface calcifications that are breaking through to the surface. ${ }^{369}$ The variability of different patterns may be attributed to the interaction of the various hydrophilic IOLs that may differ in their material composition. In this series, we report for the first time the opacification of Hanita $B$ lens, Hanita C lens, Xcellence Idea, Biotech vision care Eyecryl and U.S. optics SL-902 IOLs following intraocular air or gas injection.
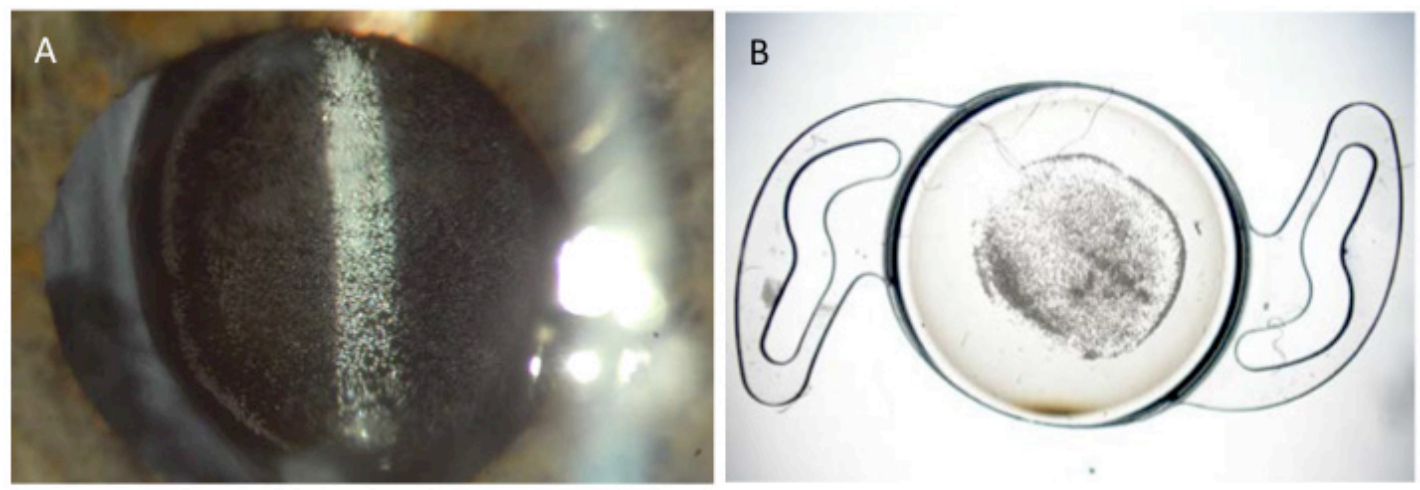

C

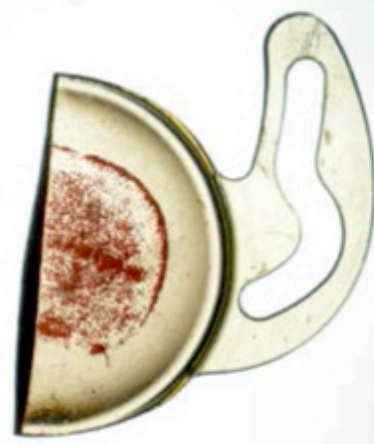

D
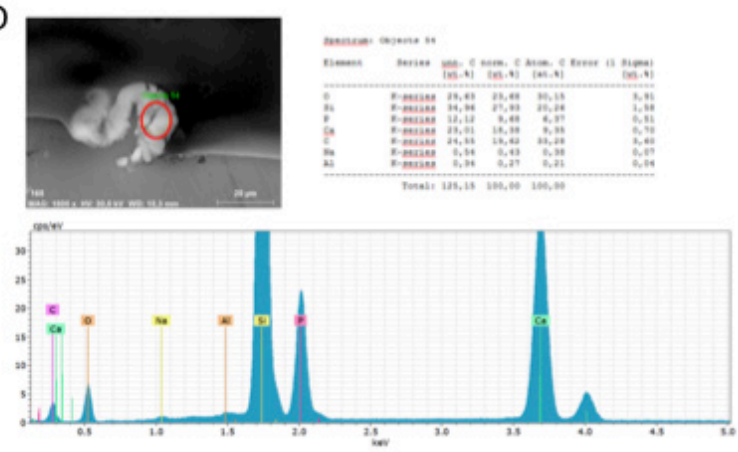

Figure 2 Case 5: (A) slit photograph showing opacification of a hydrophilic IOL at the pupillary opening not reaching the capsulorhexis edge. (B) Photograph of the explanted IOL with a rough central anterior area. (C) Alizarin red staining demonstrating positive staining for calcium. (D) Energy dispersive X-ray spectrum of the sediments shows calcium and phosphorus peaks (the silicone peak is an artefact caused by a silicone wafer, which was used for the analysis). IOL, intraocular lens. 

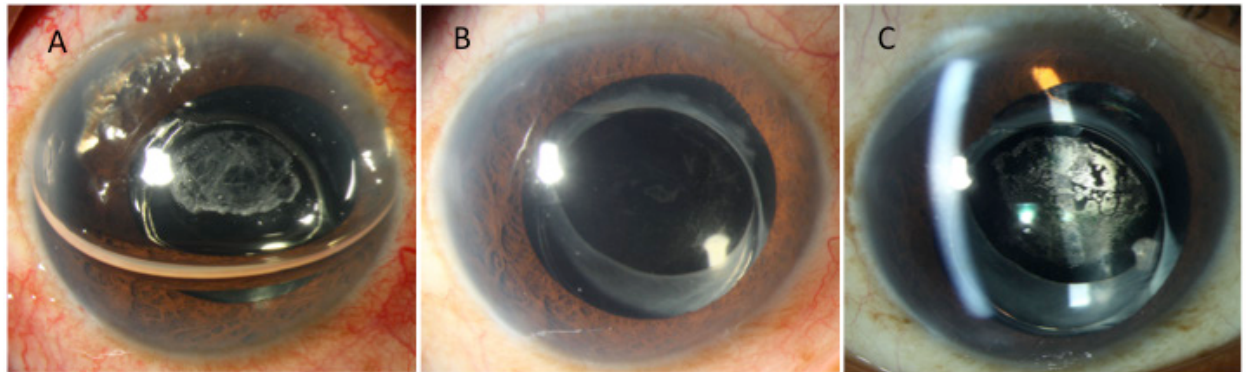

Figure 3 Case 10: (A) slit lamp photograph 1 day postoperatively after phacoemulsification and hydrophilic IOL implantation combined with pars plana vitrectomy and SF6 gas intravitreal injection due to retinal detachment. In this patient, the gas migrated to the anterior chamber. Drying of the anterior surface of the IOL was noted. (B) Photograph taken at 1-month follow-up visit. The gas disappeared and the IOL looked transparent. (C) Photograph taken at 8-month follow-up visit. Anterior opacification of the IOL is evident. The IOL was not explanted due to poor visual potential of the operated eye. IOL, intraocular lens; SF6, sulfur hexafluoride.

PPV has become the preferred surgical procedure for RD in patients with pseudophakia. ${ }^{11}$ 15-17 Other indications such as ERM peeling and macular hole surgery increased the number of PPV performed annually. ${ }^{11}$ Patients over 65 years of age were found to have the highest rates of vitrectomy. ${ }^{11}$ Some of these patients may be pseudophakic before PPV surgery, and in many, a combined phacoemulsification and PPV is performed due to existing cataract. ${ }^{11}$ We analysed the operative notes and patient charts at Kaplan Medical Centrerduring 7 years from 2009 to 2015 (unpublished data). There were 166 PPVs with intravitreal gas injection with hydrophilic IOLs. The incidence of IOL opacification was $7 \%$. In four patients, the IOLs were explanted, and on eight additional IOLs, opacification was documented. Two out of these 12 patients have diabetes. The numbers are too small to determine if diabetes was a risk factor.
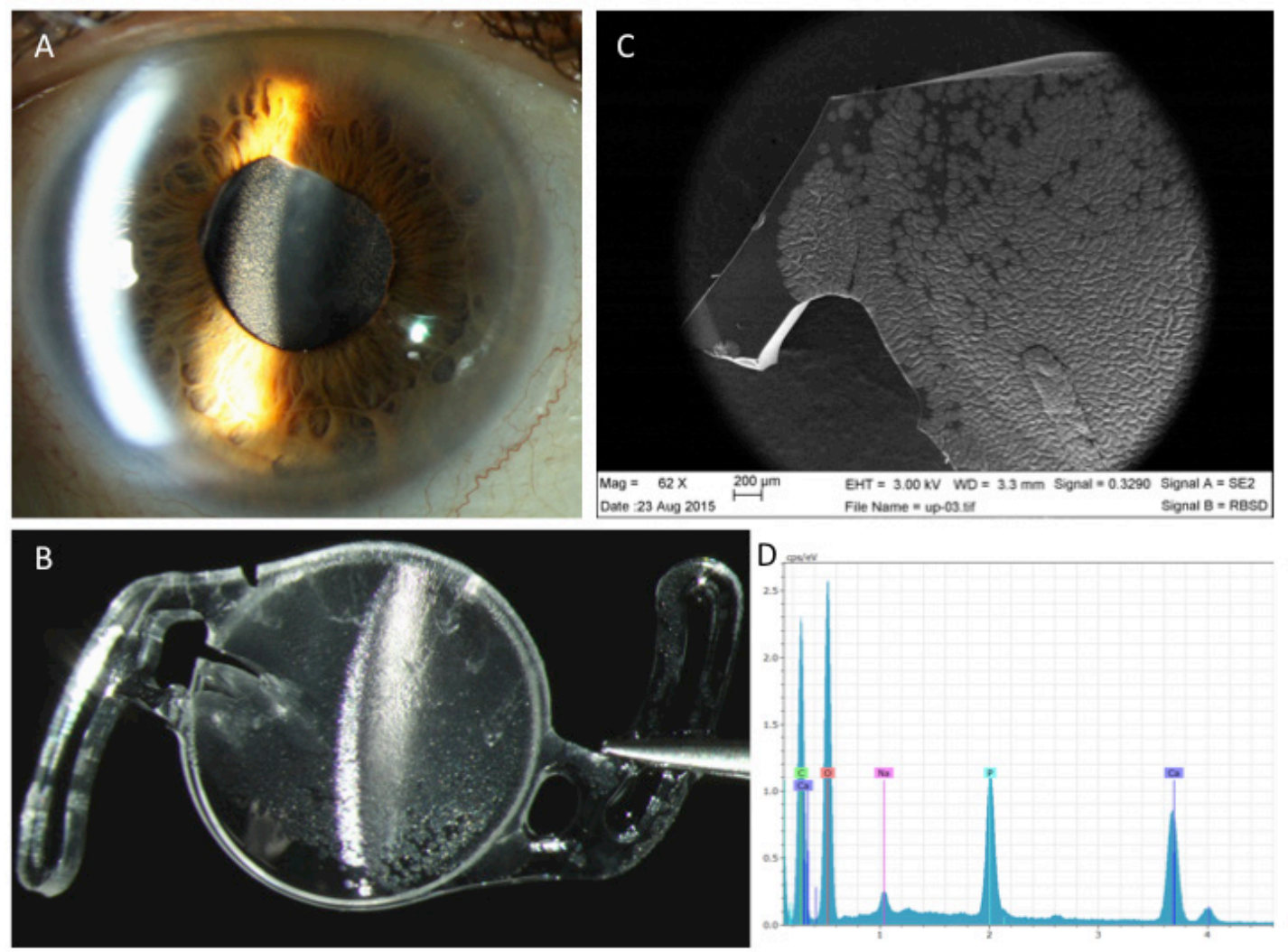

Figure 4 Case 2: (A) slit photograph showing an opacified hydrophilic IOL optic implanted in the sulcus. The pupil is dilated. (B) Photograph of the explanted IOL demonstrating sedimentation that covers the entire anterior optic area and extends to the haptics. (C) Low magnification image of the IOL by SEM. The sediments cover the entire optic area and part of the haptics. (D) Energy dispersive X-ray spectrum of the sediments shows calcium and phosphorus peaks (sodium and chlorine are artefacts from the saline solution). IOL, intraocular lens; SEM, scanning electron microscopy. 

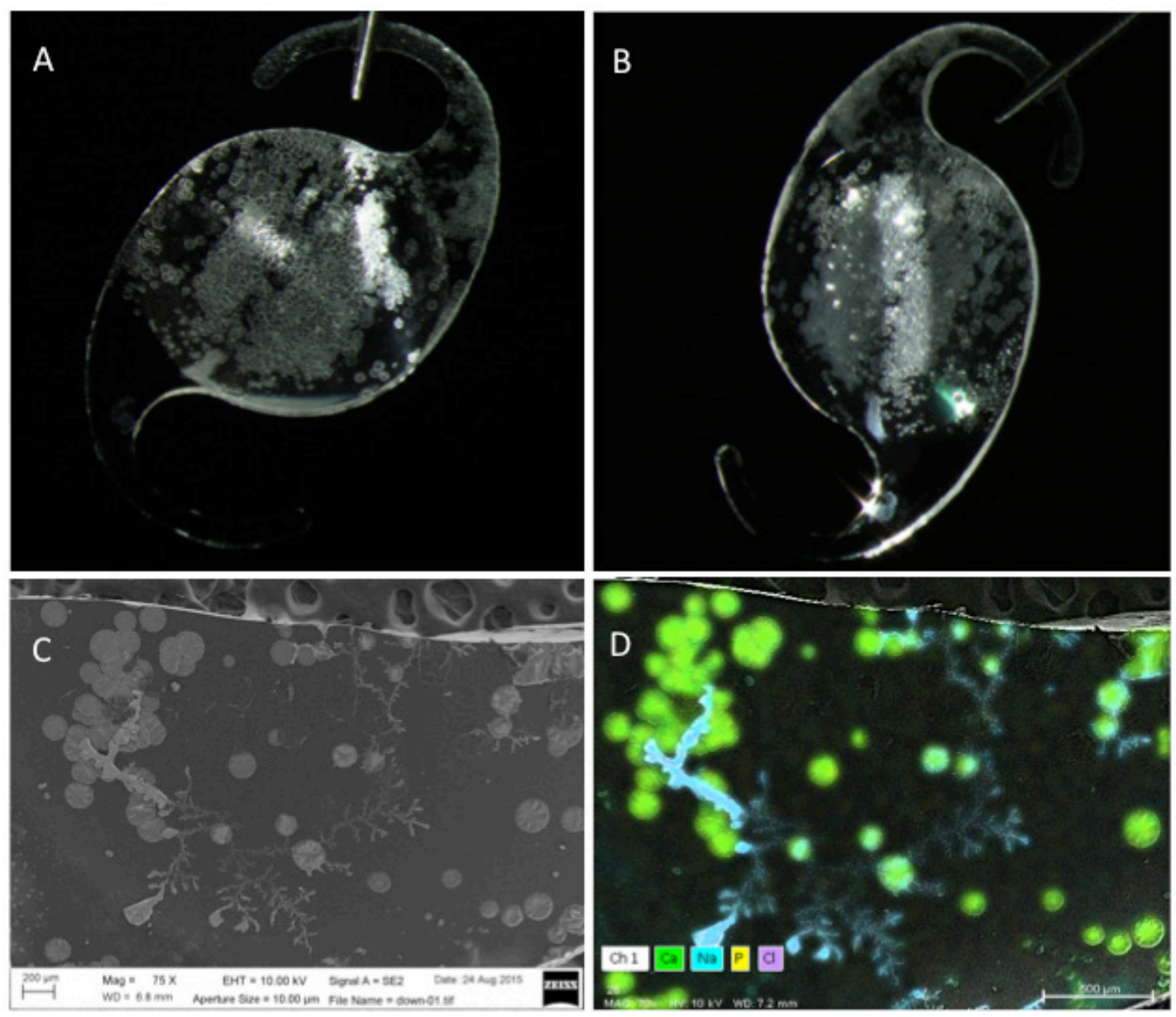

Figure 5 Case 3: (A and B) photographs showing an explanted hydrophilic IOL demonstrating sedimentation on the anterior optic area (A) and the posterior optic area (B). (C) Image of the sediments on the posterior IOL optic by SEM. (D) element mapping shows calcium (marked with green) inside the sediments. IOL, intraocular lens; SEM, scanning electron microscopy.

Manufactures of hydrophilic IOLs alert in their IFU against IOL dehydration. ${ }^{12} 13$ We can hypothesise that the greater the occupancy of posterior chamber gas $(\%)$, the greater the chance of IOL dehydration and subsequent opacification. In ERM or macular hole surgery, at the conclusion of the vitrectomy, a partial (rather than full) gas bubble and a non-expandable gas composition may be preferred to allow fluid meniscus adjacent to the IOL preventing the IOL from drying. The patient may be instructed to sleep face down, to diminish contact between the gas and the IOL similar to phakic patients undergoing PPV with gas injection. In RD surgery, which is sight threatening, the immediate goal is reattachment of the retina and gas application and head position is derived from the clinical condition. The prevalence of surface opacification of IOLs may be underdiagnosed since it can allow reasonable vision. In a series of five opacified IOLs after DSAEK, only one IOL was exchanged due to decrease in vision. ${ }^{3}$ However, optical bench analysis of explanted opacified IOLs following endothelial keratoplasty demonstrated deterioration of the optical quality. ${ }^{7}$ Due to gradual decrease in the optical clarity of the opacified IOLs, the interval between the beginning of opacification to the actual explantation may last between months to years. ${ }^{2}$ In three of our patients, IOL exchange improved BCVA to 6/10 (cases 1, 6 and 7). In other cases, vision remained poor due to macular dysfunction. In our 11th patient, the sedimentation on the IOL surface was not homogenous, leaving a relatively clear central zone still allowing a 6/12 vision. The patient experienced glare but refused IOL explantation.

In conclusion, injected intravitreal gas during PPV may cause opacification of hydrophilic IOLs due to surface $\mathrm{Ca} / \mathrm{P}$ sedimentation. Due to the rise in PPV procedures performed annually, ${ }^{11}$ the incidence of IOL opacification following this procedure is expected to increase. A significant percentage of patients may be pseudophakic at the time of surgery with a hydrophilic acrylic IOL already implanted. It is important to alert these patients about the possible IOL opacification following PPV. When performing simultaneous PPV with phacoemulsification, a hydrophobic acrylic IOL may be preferred.

Contributors Study concept and design (ALM, TT and RK); data collection (ALM, $\mathrm{TT}, \mathrm{MB}$ and $\mathrm{EE}$ ); analysis and interpretation of data (ALM, TT, RK, $A B$ and IKA); writing the manuscript (ALM, $T$ and MB); critical revision of the manuscript ( $A B$, GUA and RK); ALM and TT contributed equally to this publication in analysing the data and writing the manuscript. All authors read and approved the final manuscript. 
Funding The David J. Apple International Laboratory for Ocular Pathology, Germany, is supported by agrant from the Klaus Tschira Foundation.

Competing interests None declared.

Patient consent Not required.

Provenance and peer review Not commissioned; externally peer reviewed.

Open access This is an open access article distributed in accordance with the Creative Commons Attribution Non Commercial (CC BY-NC 4.0) license, which permits others to distribute, remix, adapt, build upon this work non-commercially, and license their derivative works on different terms, provided the original work is properly cited, appropriate credit is given, any changes made indicated, and the use is non-commercial. See: http://creativecommons.org/licenses/by-nc/4.0/

\section{REFERENCES}

1. Werner L, Wilbanks G, Ollerton A, et al. Localized calcification of hydrophilic acrylic intraocular lenses in association with intracameral injection of gas. J Cataract Refract Surg 2012;38:720-1.

2. Werner L, Wilbanks G, Nieuwendaal CP, et al. Localized opacification of hydrophilic acrylic intraocular lenses after procedures using intracameral injection of air or gas. J Cataract Refract Surg 2015;41:199-207.

3. Park JC, Habib NE, Moate RM. Intraocular lens opacification after corneal endothelial keratoplasty: electron microscopy and $\mathrm{x}$-ray element spectroscopy analysis. J Cataract Refract Surg 2015:41:140-5.

4. MacLean KD, Apel A, Wilson J, et al. Calcification of hydrophilic acrylic intraocular lenses associated with intracameral air injection following DMEK. J Cataract Refract Surg 2015;41:1310-4.

5. Saeed MU, Singh AJ, Morrell AJ. Sequential Descemet's membrane detachments and intraocular lens haze secondary to SF6 or C3F8. Eur J Ophthalmol 2006;16:758-60.

6. Dhital A, Spalton DJ, Goyal S, et al. Calcification in hydrophilic intraocular lenses associated with injection of intraocular gas. Am J Ophthalmol 2012;153:1154-60.
7. Giers BC, Tandogan T, Auffarth GU, et al. Hydrophilic intraocular lens opacification after posterior lamellar keratoplasty - a material analysis with special reference to optical quality assessment. BMC Ophthalmol 2017;17:150.

8. Purbrick RM, Stavrakas $\mathrm{P}$, Porooshani $\mathrm{H}$, et al. Calcification of a Rayner Centerflex $570 \mathrm{H}$ hydrophilic acrylic intraocular lens following vitrectomy for retinal detachment: a clinicopathologic report. Eur $J$ Ophthalmol 2010;20:1082-5.

9. Walker NJ, Saldanha MJ, Sharp JA, et al. Calcification of hydrophilic acrylic intraocular lenses in combined phacovitrectomy surgery. J Cataract Refract Surg 2010;36:1427-31.

10. Lee SJ, Choi JH, Sun HJ, et al. Surface calcification of hydrophilic acrylic intraocular lens related to inflammatory membrane formation after combined vitrectomy and cataract surgery. J Cataract Refract Surg 2010;36:676-81.

11. Wubben TJ, Talwar N, Blachley TS, et al. Rates of vitrectomy among enrollees in a United States managed care network, 2001-2012. Ophthalmology 2016;123:590-8.

12. Rayner Intraocular Lenses Ltd. Rayner C-flex $570 \mathrm{C}$ and $970 \mathrm{C}$ Hydrophilic IOLs Instructions for Users. East Sussex ENGLAND 2012.

13. Medicontur Medical Engineering Ltd. Medicontur Intraocular lenses Instructions for Users. Zsámbék HUNGARY 2016.

14. Kim CJ, Choi SK. Analysis of aqueous humor calcium and phosphate from cataract eyes with and without diabetes mellitus. Korean J Ophthalmol 2007;21:90-4.

15. Heimann H, Bartz-Schmidt KU, Bornfeld N, et al. Scleral buckling versus primary vitrectomy in rhegmatogenous retinal detachment: a prospective randomized multicenter clinical study. Ophthalmology 2007;114:2142-54.

16. Sharma YR, Karunanithi S, Azad RV, et al. Functional and anatomic outcome of scleral buckling versus primary vitrectomy in pseudophakic retinal detachment. Acta Ophthalmol Scand 2005:83:293-7.

17. Brazitikos PD, Androudi S, Christen WG, et al. Primary pars plana vitrectomy versus scleral buckle surgery for the treatment of pseudophakic retinal detachment: a randomized clinical trial. Retina 2005;25:957-64. 